\title{
Novas gerações no mercado de trabalho: expectativas renovadas ou antigos ideais?
}

\author{
New generations in the job market: renewed expectations or old ideals?
}

\author{
Flávia de Souza Costa Neves Cavazotte ${ }^{1}$ \\ Ana Heloisa da Costa Lemos ${ }^{2}$ \\ Mila Desouzart de Aquino Viana ${ }^{3}$
}

\begin{abstract}
Resumo
Em meio a transformações nas carreiras e relações produtivas na atualidade, (BALASSIANO e COSTA, 2006; DUTRA, 2010), uma nova geração de profissionais está entrando no mercado de trabalho. Essa geração tem sido caracterizada pela literatura não acadêmica como sensivelmente diferente das antecessoras (ALSOP, 2008; MUNRO, 2009). No entanto, em estudos científicos, as diferenças observadas parecem bem menos acentuadas (CENNAMO e GARDNER, 2008; WONG, GARDINER, LANG et al., 2008). As mudanças no âmbito das carreiras e o ingresso no mercado de trabalho dessa nova geração motivaram a realização deste estudo que objetivou conhecer as expectativas de jovens profissionais em formação quanto às recompensas tangíveis e intangíveis que desejam obter no trabalho, através de entrevistas com estudantes do curso de graduação em Administração de universidades privadas do Rio de Janeiro. Diante de uma pergunta ampla acerca do que desejariam encontrar nas organizações, jovens com idades entre 20 e 28 anos revelaram seus sonhos e anseios. A análise dos relatos sugere que há mais em comum entre os membros da geração $Y$ e seus antecessores do que a literatura não acadêmica nos faria crer. As observações desta pesquisa oferecem suporte à noção de que jovens funcionários talvez estabeleçam contratos psicológicos que favorecem o prazer, a liberdade e o envolvimento social. Ao mesmo tempo indicam que o novo parece coexistir com o tradicional, pois anseios contemporâneos combinam-se a desejos comuns às gerações anteriores, reforçando a percepção de que existem expectativas relacionadas ao trabalho que subsistem, a despeito de mudanças objetivas na esfera produtiva.
\end{abstract}

Palavras-chave: Sentido do Trabalho. Geração Y. Carreira.

\begin{abstract}
Amid the changes in careers and labor relations in today's workplace, (BALASSIANO and COSTA, 2006; DUTRA, 2010), a new generation of professionals is entering the job market. This generation has been characterized by the nonacademic literature as significantly different from its predecessors (ALSOP, 2008; MUNRO, 2009). However, scientific studies have also suggested that such differences could be much less pronounced (CENNAMO and GARDNER, 2008; WONG, GARDINER, LANG et al., 2008). The changing nature of careers and the entrance of this new generation into the job market have motivated this study, which aims to examine the expectations of young workers regarding the
\end{abstract}

Artigo submetido em 19 de novembro de 2010 e aceito para publicação em 04 de agosto de 2011.

1

Doutora em administração pela Virginia Commonwealth University; Professora do quadro principal da Pontifícia Universidade Católica do Rio de Janeiro. Endereço: Rua Marquês de São Vicente, n²25, Gávea, CEP 22451-900, Rio de Janeiro - RJ, Brasil. E-mail cavazotte@gmail.com

2

Doutora em sociologia pelo IUPERJ; Professora do quadro principal da Pontifícia Universidade Católica do Rio de Janeiro. Endereço: Rua Marquês de São Vicente, n²25, Gávea, CEP 2245 1-900, Rio de Janeiro - RJ, Brasil. E-mail aheloisa@iaq.puc-rio.br

${ }^{3}$ Mestre em administração pela Pontifícia Universidade Católica do Rio de Janeiro; Professora da Pontifícia Universidade Católica do Rio de Janeiro. Endereço: Rua Marquês de São Vicente, n²25, Gávea, CEP 22451-900, Rio de Janeiro - RJ, Brasil. E-mail mila.viana@esp.puc-rio.br 
intrinsic and extrinsic rewards they wish to attain in the workplace through interviews with undergraduate students enrolled in management programs offered by private universities in Rio de Janeiro. As they addressed an open question regarding what they wished to find in the organizations, young adults ranging from 20 to 28 years old revealed their dreams and concerns. The analysis of the reports suggests that there is more in common between members of Generation $Y$ and its predecessors than the non-academic literature would have us believe. The observations of this study support the notion that young employees may establish psychological contracts that favor pleasure, freedom and social involvement. On the other hand, new and conventional expectations seem to coexist, since such contemporary concerns come together with aspirations longed for by previous generations, reinforcing the perception that there are work-related expectations that remain, in spite of objective changes in the productive sphere.

Keywords: Meaning of Work. Generation Y. Career.

\section{Introdução}

A literatura dedicada a debater os temas relacionados à gestão de pessoas e relações de trabalho tem sido pródiga em apontar as intensas transformações que vem afetando o mundo do trabalho nas duas últimas décadas. Instabilidade dos vínculos empregatícios, aumento da competição nos ambientes de trabalho; fim das carreiras organizacionais; surgimento das carreiras sem fronteiras e proteanas; preocupação crescente com a empregabilidade são alguns dos assuntos recorrentes nos inúmeros artigos e livros voltados para discutir o trabalho contemporâneo (BALASSIANO e COSTA, 2006; DUTRA, 2010). As transformações em curso colocam as organizações diante do desafio de seguir motivando e envolvendo uma força de trabalho com menor propensão a desenvolver laços de lealdade e a comprometer-se com as organizações nas quais atuam: se a efemeridade dos vínculos empregatícios é a promessa do mundo produtivo desse início de século, a ligação volúvel tem sido a resposta frequente dos trabalhadores em um contexto em que "tudo o que é sólido, desmancha no ar" (BERMAN, 1988).

Nesse cenário, que combina competição intensa entre as empresas, necessidade crescente de recursos humanos altamente qualificados nas organizações e instabilidade das relações de trabalho, a preocupação com os aspectos que afetam a motivação e o comprometimento da força de trabalho ganha proeminência. Apesar de nunca ter saído de cena - desde que os experimentos de Hawthorne indicaram que o envolvimento subjetivo do trabalhador afetava a produtividade organizacional, incontáveis estudos abordam a temática - o desafio e a importância de se motivar e comprometer os trabalhadores vem sendo alvo de interesse não só dos estudiosos do tema, mas também dos gestores, cada vez mais instados a apresentar resultados em suas áreas de atuação. Ao desafio de comprometer indivíduos em organizações que não podem oferecer muito mais do que ganhos atraentes no curto prazo e instabilidade empregatícia no longo prazo (CASTEL, 1998), some-se a dificuldade em lidar com os novos entrantes no mercado de trabalho, jovens com valores e expectativas profissionais semelhantes em certos aspectos às gerações anteriores, mas diferentes o suficiente para serem alvos de estudos que procuram entender suas peculiaridades.

A constatação da relevância da temática comprometimento organizacional, no contexto atual das relações de trabalho, e do desafio adicional de entender os fatores capazes de gerar o comprometimento dos novos integrantes da força de trabalho motivaram a realização de uma pesquisa que tentou conhecer as expectativas desses no que tange à inserção nas organizações, com ênfase nas recompensas tangíveis e intangíveis obtidas no trabalho. A referida pesquisa, inspirada na tradição fenomenológica, teve como foco estudantes do curso de graduação em Administração de Empresas de duas universidades privadas do Rio de Janeiro. Diante de uma pergunta bastante ampla acerca do que o entrevistado desejaria encontrar na organização em que irá trabalhar no futuro próximo, jovens com idades entre 20 e 28 anos revelaram seus sonhos e anseios. A análise do conteúdo das entrevistas permitiu conhecer um pouco mais as expectativas desses futuros profissionais com relação às recompensas tangíveis e intangíveis obtidas no trabalho, expectativas essas que 
devem ser olhadas com atenção pelas organizações que querem efetivamente contar com uma força de trabalho motivada, comprometida e produtiva, nessa primeira metade do século XXI.

Para apresentar e discutir os achados da pesquisa em questão, estruturou-se o presente artigo em cinco tópicos, incluindo esse. O segundo tópico foi dedicado a discutir a literatura recente sobre o sentido do trabalho, as carreiras contemporâneas, a nova geração e o comprometimento organizacional; o terceiro apresenta os aspectos metodológicos da pesquisa; o quarto a análise das entrevistas e o último a discussão dos resultados, conclusões, limitações do estudo e sugestões para futuras investigações.

\section{Referencial Teórico}

\section{Sobre o sentido do trabalho}

O sentido do trabalho é um conceito complexo e envolve um sistema dinâmico e multidimensional de padrões de valores individuais e sociais sobre o trabalho. Valores, i.e., crenças sobre que meios e fins são preferíveis do ponto de vista pessoal ou social (ROKEACH, 1973), estabelecem aquilo que se considera bom ou ruim, desejável ou indesejável, o que merece ou não o investimento de nosso esforço e energia. Os valores de um grupo sobre o trabalho organizam suas necessidades, desejos e objetivos em função de sua importância e prioridade relativas e estão associados com as atitudes e comportamentos sociais dos indivíduos nesse contexto (NORD e BRIEF, 1990).

Um dos principais estudos sobre o sentido do trabalho, realizado pelo grupo de pesquisa internacional Meaning of Working International Research Team (MOW, 1987), discute o tema a partir de cinco grandes dimensões: 1) a centralidade do trabalho para as pessoas, comparativamente a outros domínios da vida, como a família e o lazer; 2) as normas sociais sobre direitos e deveres do indivíduo no trabalho; 3) o papel atribuído ao trabalho pelos indivíduos em sua vida; 4) a importância relativa das recompensas tangíveis e intangíveis obtidas no trabalho; e 5) a identificação do indivíduo com os diferentes papéis que exerce no ambiente de trabalho. Segundo os autores, todas as dimensões seriam influenciadas tanto por fatores sociais como por características individuais e pelas experiências vivenciadas no trabalho ao longo do tempo. $\mathrm{O}$ foco do presente estudo é a quarta dimensão mencionada, referente às recompensas priorizadas no trabalho.

Sendo historicamente e culturalmente relativo, o sentido do trabalho pode variar para um mesmo indivíduo ou coletividade ao longo do tempo, e entre pessoas ou grupos em um dado momento histórico. O trabalho propriamente dito sofreu consideráveis transformações ao longo do último século, particularmente em função das mudanças tecnológicas observadas na era pós-industrial. Biotecnologias, automação, multimedia e redes computacionais globais representam alguns dos novos recursos que engendraram profundas transformações nos diversos setores produtivos. Com o desenvolvimento e a incorporação de novas ferramentas e técnicas, o trabalho foi transferido, em grande escala, das mãos para as mentes (HOWARD, 1995). Essas e outras transformações influenciam as peculiaridades da experiência humana, o que pode provocar mudanças em padrões de sentido do trabalho ao longo do tempo.

Se, por um lado, assumir a total rigidez desse sistema de valores seria incompatível com qualquer noção de mudança social, por outro, assumir sua absoluta instabilidade também não seria compatível com a continuidade observada em diversas transações humanas. Assim, apesar de ser dinâmico em sua essência e construído socialmente ao longo de diferentes experiências associadas ao universo ocupacional, acredita-se que o sentido do trabalho para as pessoas tenha relativa estabilidade e esteja também associado aos seus valores em outras esferas da vida (NORD e BRIEF,1990).

Os sistemas de valores sobre o trabalho parecem variar entre grupos imersos em contextos sócio-culturais distintos e em função de seu perfil demográfico. No final da década de 80 , pesquisadores observaram que 
uma proporção muito maior de trabalhadores no Japão esposava valores expressivos relativos ao trabalho priorizando autonomia, interesses no trabalho propriamente dito e uma boa combinação entre habilidades e trabalho realizado -do que nos Estados Unidos e na Alemanha, onde a maioria dos trabalhadores esposava valores instrumentais, priorizando salário e segurança (MOW,1987). O estudo verificou também que fatores como idade, educação, ocupação e gênero seriam relevantes para a compreensão de diferenças observadas na importância relativa das recompensas obtidas pelo trabalho.

As implicações do sentido do trabalho para as organizações e sociedades são amplas, uma vez que ele determina aquilo que as pessoas julgam ser legítimo no contexto ocupacional, o que estão ou não dispostas a tolerar, como os custos que as elites aceitam para direcionar as várias atividades do mundo do trabalho, até a facilidade com que indivíduos se dispõem a mudar hábitos para satisfazer os imperativos de novas tecnologias. Portanto, conhecer o sentido do trabalho para indivíduos e grupos hoje é um passo essencial para compreender o comportamento das pessoas no trabalho num mundo pós-moderno, no qual a dimensão profissional ainda tem papel fundamental para a formação da identidade e para o bem estar das pessoas.

Do ponto de vista individual, o sentido do trabalho estabelece as bases sobre as quais se edificam princípios e preferências dos trabalhadores em relação à esfera ocupacional, sendo também um elemento formador de objetivos, escolhas e atitudes em relação à carreira. No entanto, se por um lado as primeiras experiências profissionais teriam um importante papel na construção do sentido que jovens profissionais atribuem ao trabalho, por outro, jovens também se situariam na linha de frente da disseminação de novos valores e mudanças culturais relativas ao trabalho e à carreira em uma sociedade (VAN DER VELDE, FEIJ e VAN EMMERIK, 1998), incluindo a natureza dos contratos de trabalho estabelecidos pelos indivíduos com as organizações.

\section{Sobre as Novas Configurações das Carreiras}

A literatura que discute a configuração atual das carreiras destaca uma transformação substantiva em sua estrutura. Em oposição às carreiras organizacionais tradicionais, delineiam-se as denominadas "carreira sem fronteiras" e "carreira proteana", refletindo em sua constituição mudanças no mercado de trabalho. Autores como Arthur e Rousseau (1996) apontam para o declínio das carreiras organizacionais, que ofereciam aos indivíduos a perspectiva de ascensão periódica em uma mesma empresa, o que permitia a construção de vínculos de longo prazo entre trabalhador e organização. O auge dessa configuração situou-se entre o pósguerra e os anos 70, o que condicionou as gerações que ingressaram no mercado de trabalho nesse período a planejarem suas carreiras em simbiose com as organizações. Não era incomum, mas desejável, aspirar a um emprego em uma única empresa, por toda a vida. Nesse contexto emprego e carreira eram associados, de forma indelével, à inserção em uma grande organização (ARTHUR e ROUSSEAU,1996; DUTRA, 2010).

Os pesquisadores destacam, todavia, que esse formato de carreira começa a entrar em declínio nos anos 80 , em decorrência do processo de reestruturação produtiva, que vêm provocando mudanças significativas na forma como se estrutura o mercado de trabalho, mudanças estas que tem levado à configuração dos novos desenhos de carreiras. É nesse contexto de mudanças que se delineia a carreira sem fronteiras, entendida como trajetória profissional individual, construída a partir da inserção em diferentes organizações, fundada em diversas experiências de trabalho e não mais como sinônimo de trajetória profissional ascendente em uma única organização. Essa concepção postula a existência de uma relação independente entre organização e indivíduo, uma concepção de carreira sem fronteiras. Os indivíduos passam a ser os responsáveis pela gestão de suas carreiras, construídas não mais com base em cargos lineares oferecidos por uma mesma organização, mas pelo trânsito entre diferentes organizações, movimento este motivado tanto pela procura de novos desafios profissionais quanto pela diminuição de oportunidades periódicas de ascensão nas organizações contemporâneas. A concepção de carreira associada a uma única organização passa a ser vista como obsoleta e a mobilidade se dá mais intensamente entre as fronteiras organizacionais do que em seu interior. A carreira sem fronteiras prevê, em última instância, o desenvolvimento de uma relação independente entre organização 
e indivíduo, exigindo do mesmo capacidade de decidir, constantemente, o caminho de desenvolvimento profissional a seguir (ARTHUR e ROUSSEAU, 1996).

Outra tipologia presente na literatura sobre carreiras, a denominada carreira proteana expressa a necessidade de mudanças frequentes nos rumos profissionais. O conceito de carreira proteana, proposto por Hall e Moss (1998), guarda relação com o conceito de carreira sem fronteiras: a designação proteana faz analogia ao polimorfismo do deus Proteu, quando busca exemplificar a combinação entre a antiga concepção de contratos relacionais - baseados na expectativa de um relacionamento de longo prazo que fosse satisfatório para ambos os lados - e a concepção de contrato transacional, baseado em relações e trocas utilitárias e de curto prazo. O contrato proteano pressupõe a combinação dessas duas condições: a continuidade do relacionamento passa a depender fundamentalmente do desempenho do trabalhador e a troca transacional é resultante da capacidade da organização oferecer oportunidades recompensadoras ao trabalhador. Ademais, na perspectiva da carreira proteana, cabe ao trabalhador desenvolver uma progressiva visão holística sobre as organizações. A capacidade de um profissional seria apenas o ponto de partida para sua inserção no mercado de trabalho e o marco inicial de uma constante busca por aperfeiçoamento e pela interdisciplinaridade. A meta é ser um profissional capaz de entender a organização como um todo e as possibilidades de progressão ampliam-se para além da trajetória vertical: noções como inclusão/centralidade em uma determinada área e progressão interfuncional passam a integrar o léxico da carreira proteana. Hall e Moss (1998) postulam que a carreira proteana é condizente com um novo contrato psicológico, onde a segurança do longo prazo é substituída pela volatilidade do curto prazo, caracterizada por mudanças frequentes, autoinvenção, autonomia, habilidade para novos aprendizados, habilidades para redirecionar a carreiras e capacidade de construir relações.

\section{Sobre o sentido do trabalho para as diferentes gerações}

Segundo as teorias sobre gerações, pessoas nascidas num mesmo período compartilham experiências de vida históricas e sociais e essas vivências comuns poderiam afetar de forma similar seu padrão de resposta a situações e instituições, como seus valores e crenças sobre as organizações, sua ética de trabalho, as razões pelas quais trabalham, seus objetivos e aspirações na vida profissional e seu comportamento no trabalho (SMOLA e SUTTON, 2002). A literatura não é muito sistemática quanto às datas de nascimento que delimitariam estas gerações embora haja diversas inconsistências, de maneira geral, são indicados como "Baby Boomers" (Boomers) os nascidos entre a década de 1940 e o início da década de 1960, como Geração X (Xrs) os nascidos entre meados da década de 1960 e o final da década de 1970 e a chamada "geração milênio" ou "geração Y" (Yrs), aqueles nascidos a partir de 1980 (ALSOP, 2008; SMOLA e SUTTON, 2002). Os dois primeiros grupos representam a maior proporção de indivíduos na força de trabalho de hoje.

Alguns autores descrevem os Boomers como uma coorte que tenderia a valorizar a segurança no trabalho, que seria mais leal e apegada às empresas, mais diligente e dedicada ao trabalho, mais tradicional e habituada a diferenciais de autoridade, interessada pela aquisição de poder e status ao longo da carreira e por recompensas extrínsecas em troca de seu comprometimento, porém com mais dificuldade para equilibrar a vida pessoal e a profissional (SMOLA e SUTTON, 2002; CENNAMO e GARDNER, 2008; WONG, GARDINER, LANG et al., 2008). Já os Xrs são descritos por estes mesmos autores como um grupo mais interessado em ganhos de oportunidade, que seria mais cínico e individualista, menos leal às organizações, mais afeito à mudança e mais inclinado a deixar uma empresa em troca de desafios e melhores recompensas, menos suscetível à autoridade formal, embora mais dependente de feedback, e mais preocupado com seus objetivos pessoais e com o equilíbrio entre a vida pessoal e a profissional.

O último grupo, os Yrs, representa o segmento mais jovem atuando no mercado de trabalho nos dias atuais. Um dos grandes marcos que parecem ter definido as experiências desse grupo foi o desenvolvimento da tecnologia computacional, em particular em seus desdobramentos mais recentes como a expansão na Internet dos sites de relacionamento e a difusão do uso de simulação em jogos virtuais de console e web-based 
(ALSOP, 2008; LOUGHLIN e BARLING, 2001; PROSERPIO e GIOIA, 2007; SMOLA e SUTTON, 2002). Ensaios narrativos não acadêmicos descrevem a geração $\mathrm{Y}$ como sendo composta por indivíduos acostumados a lidar com um número muito grande de informações, afeitos à multidisciplinaridade e à interconectividade com o resto do mundo (ALSOP, 2008; ERICKSON, 2008; HUNTLEY, 2006). Estes jovens são caracterizados como mais acostumados com mudanças, menos inclinados a priorizar a segurança no trabalho, mais ansiosos por novos desafios e mais tolerantes com os erros do que as gerações anteriores (ALSOP, 2008; MUNRO, 2009). Alguns autores sugerem que os Yrs desejam assumir responsabilidades e participar dos processos de tomada de decisão, esperam ter um rápido crescimento dentro das organizações, ao mesmo tempo em que demandam o desenvolvimento de suas competências e condições de trabalho com maior flexibilidade (ALSOP, 2008; HUNTLEY, 2006; LOUGHLIN e BARLING, 2001; MUNRO, 2009). São também descritos como membros de uma geração mais ativa socialmente do que a anterior, com preferência por atuar em empresas que sejam referência em termos de ética e responsabilidade social (ALSOP, 2008; HUNTLEY, 2006).

Alguns pesquisadores têm se dedicado a estudar comparativamente os sistemas de valores esposados por esses grupos. Cennamo e Gardner (2008) verificaram maior desejo por status e autonomia no trabalho entre indivíduos da geração Y do que nas gerações anteriores em seu estudo com cidadãos da Nova Zelândia. Em um estudo com australianos, Wong e seus colaboradores (WONG, GARDINER, LANG et al., 2008) observaram que indivíduos da geração Y se apresentaram um pouco mais ambiciosos, centrados na carreira e inclinados a apreciar papéis e metas de trabalho desafiadoras do que Boomers, mas não significativamente diferentes da geração $\mathrm{X}$ nesses mesmos quesitos. Os autores também observaram níveis mais baixos de otimismo apenas entre membros da geração Y e os Boomers e níveis mais altos de consciência apenas entre os Yrs e os Xrs. Membros da geração Y também apresentaram níveis um pouco mais altos de motivação por oportunidades de interação com outras pessoas no trabalho e por progressão na carreira do que os Boomers, e mais baixos de motivação por poder do que os dois grupos geracionais anteriores. Há, no entanto, questionamentos quanto à possibilidade de muitas dessas diferenças atribuídas à geração serem de fato um produto do amadurecimento, desenvolvimento na carreira e fase no ciclo de vida em que as pessoas se encontram (MACHY, GARDNER e FORSYTH, 2008).

Ainda em linha com o debate acerca das gerações, Twenge e Campbell (2008) analisaram diferenças geracionais a partir de resultados observados em inventários de personalidade e comportamento preenchidos por cerca de 1,4 milhões de universitários americanos entre 1930 e os dias atuais, neutralizando assim os efeitos do amadurecimento e da fase no ciclo de vida sobre as diferenças observadas. $\mathrm{O}$ estudo verificou entre os Yrs níveis mais elevados de auto-estima, narcisismo, ansiedade e depressão, níveis mais baixos de necessidade de aprovação social, locus de controle mais externo e mulheres com traços mais agênticos do que nas gerações anteriores. Os autores discutem que algumas das características verificadas no estudo fariam dessa geração indivíduos com elevada necessidade de satisfação, com menor propensão a assumir responsabilidade pelo sucesso ou fracasso de projetos e com níveis de stress mais elevados. Tais observações sugerem que um olhar mais cuidadoso sobre esse grupo pode ser útil tanto do ponto de vista da gestão e engajamento dos Yrs nas organizações, como da perspectiva de saúde mental e bem estar no trabalho dessa nova geração.

\section{Comprometimento organizacional: implicações para a nova geração}

O comprometimento de um funcionário com a empresa em que atua é uma atitude particularmente importante para os negócios, em vista de suas associações com outras atitudes sobre o trabalho, como a satisfação com o emprego, e com comportamentos dos indivíduos que influenciam a organização, como o desempenho em tarefas e a rotatividade voluntária (COOPER-HAMIK e VISWESVARAN, 2005; KLEIN, MOLLOY e COOPER, 2009; MATHIEU e ZAJAC, 1990). Há na literatura diferentes definições para o conceito (MOWDAY, STEERS e PORTER, 1979; ALLEN e MEYER, 1990), sendo que todas 
compartilham a ideia de que o comprometimento organizacional envolve formas múltiplas de ligação do indivíduo com a empresa.

Boa parte dos debates e das pesquisas de campo sobre o assunto tem como premissa conceitual a distinção entre três bases de comprometimento (ALLEN e MEYER, 1990), a saber: 1) a base afetiva, que envolve a vinculação do indivíduo com a empresa em função de fatores emocionais, da aceitação e internalização pelos indivíduos de objetivos e valores organizacionais, e do seu desejo de fazer esforços em nome da organização; 2) a base normativa, que envolve a vinculação do indivíduo à empresa em função da crença por parte do funcionário de que este é o seu dever ou sua obrigação moral como retribuição à organização pelo emprego; e 3) a base calculativa, que envolve a vinculação do funcionário com a empresa em função de ganhos pessoais conexos à manutenção do emprego atual, e da ausência de alternativas de emprego. Alguns autores sugerem que a dimensão calculativa na verdade deveria ser tratada como duas bases distintas, já que a continuação de uma associação para evitar o sacrifício de investimentos já realizados na organização é substantivamente distinta da continuação devido à escassez de alternativas ao emprego atual (BLAU, 2003; MEYER et al., 2002). Contudo, de maneira geral, pode-se dizer que indivíduos comprometidos por razões afetivas, normativas ou calculativas se mantém ligados à empresa respectivamente porque assim querem, devem ou precisam permanecer (ALLEN e MEYER, 1990).

Em sua meta-análise sobre o assunto, Mathieu e Zajac (1990) observaram que tanto características da organização (e.g.: tamanho da empresa), do trabalho (e.g.: grau de abrangência do trabalho) e das relações no trabalho (e.g.: ações das lideranças), como diferenças individuais (e.g.: nível hierárquico) parecem ser antecedentes relevantes do comprometimento. Particularmente no tocante à idade, o estudo verificou que funcionários mais jovens apresentam índices menores de comprometimento organizacional, sobretudo de base atitudinal. Discutindo especificamente as ameaças para o comprometimento, Meyer (2009) apontou para quatro fatores fundamentais verificados nas pesquisas mais recentes: 1) o alinhamento pessoaorganização, 2) a justiça organizacional, 3) o cumprimento de contratos psicológicos, e 4) a percepção de suporte da organização.

Estudos sobre o alinhamento pessoa-trabalho, i.e., sobre as discrepâncias entre aquilo que as pessoas esperam obter através do trabalho e aquilo que efetivamente acreditam obter e suas consequências são praticamente unânimes em verificar que a falta de alinhamento está associada a atitudes mais negativas em relação ao emprego (EDWARDS, 1991). Pesquisas posteriores têm corroborado estas observações (SAKS e ASHFORTH, 1997; SMITH e TZINER, 1998), além de indicar que os efeitos deletérios de discrepâncias pessoa-trabalho também estariam associados à maior ansiedade, depressão, irritação e a sintomas somáticos dos indivíduos.

No caso particular da intercessão entre alinhamento e comprometimento nas novas gerações, Cennamo e Gardner (2008) observaram efeitos mais negativos da falta de alinhamento sobre o comprometimento e a intenção de permanecer na empresa para os Yrs do que os Boomers e Xrs. A susceptibilidade do grupo mais jovem ao desengajamento em vista da frustração de suas expectativas é uma observação que inspira cautela, em particular se essas observações refletirem mais do que diferenças etárias, mas também uma tendência para as novas coortes profissionais. Assumindo que estes jovens vão compor uma fração cada vez mais representativa da força de trabalho, e dada a importância do seu comprometimento para as organizações onde atuam, compreender as expectativas do grupo e discutir suas implicações parece ser um passo importante e necessário. No entanto, há controvérsias entre a visão jornalística e o perfil dos Yrs observado na literatura acadêmica. Visando a um melhor entendimento das bases de construção do comprometimento e da formação de atitudes desse grupo, esta pesquisa procurou investigar o sentido do trabalho para ele, mais especificamente a importância relativa de suas expectativas no tocante a recompensas tangíveis e intangíveis relacionadas ao trabalho para os jovens profissionais em formação. 


\section{Aspectos Metodológicos da Pesquisa}

Tendo como referência a tradição de pesquisa fenomenológica (CRESWELL, 2007), que objetiva conhecer fenômenos humanos vivenciados por um conjunto de indivíduos, a presente investigação procurou entender as expectativas de jovens estudantes de administração com relação a sua inserção profissional futura nas organizações, com ênfase nas recompensas tangíveis e intangíveis esperadas. Apesar de não poder ser caracterizada como fenomenológica, posto que voltada para a descrição de uma situação futura e não de uma experiência vivida, típica dessa tradição, as pesquisadoras inspiraram-se nessa abordagem para se aproximarem dos sujeitos sem uma pauta prévia, sem um roteiro de entrevista estruturado, mas apenas com uma pergunta ampla, capaz de permitir que o entrevistado falasse livremente sobre o tema abordado. $\mathrm{O}$ objetivo foi evitar o direcionamento típico de entrevistas que adotam roteiros. Buscou-se, da tradição fenomenológica, a atitude de abertura, procurando deixar de lado noções preconcebidas acerca do fenômeno estudado.

A coleta de dados baseou-se em entrevistas pessoais, realizadas junto a vinte e dois alunos, com idades entre 20 e 28 anos, de cursos de graduação em Administração de duas universidades privadas do Rio de Janeiro, no segundo semestre de 2009. As entrevistas tiveram como ponto de partida a seguinte pergunta: "O que você desejaria encontrar na organização em que irá trabalhar, no futuro próximo?" A amplitude da pergunta teve o intuito de evitar influenciar ou conduzir os entrevistados a falar sobre aspectos específicos do ambiente e das recompensas disponíveis, a intenção era deixar os entrevistados livres para falarem sobre o que lhes ocorressem, fossem aspectos ligados à remuneração, às relações de trabalho, ao ambiente, às possibilidades de ascensão profissional. Essa pergunta foi o ponto de partida das entrevistas, nas quais as entrevistadoras se esforçaram por não induzir as respostas dos entrevistados, mas apenas esclarecer pontos imprecisos e pouco explorados do discurso. A abertura da pergunta permitiu que os entrevistados falassem sobre inúmeros, e eventualmente surpreendentes aspectos como fazer amigos e encontrar parceiros amorosos, no ambiente de trabalho.

Vários entrevistados já possuíam alguma experiência de trabalho, predominantemente estágios, pois eram estudantes universitários cursando do quarto período em diante. Todas as entrevistas foram gravadas e transcritas. Após a transcrição, as entrevistas foram lidas várias vezes e dessas leituras emergiram os temas comuns, indicativos das principais expectativas relativas ao trabalho nas organizações, em que sobressaem as recompensas tangíveis e intangíveis esperadas pelos entrevistados. À identificação dos temas seguiu-se a leitura da literatura que aborda as características peculiares aos jovens contemporâneos, elaborando-se, assim, a análise do material obtido.

\section{Análise das Entrevistas}

\section{O que os jovens desejam ?}

A análise das entrevistas teve como objetivo identificar as principais expectativas, relacionadas ao trabalho e às recompensas tangíveis e intangíveis propiciadas pelas organizações, que emergiram dos depoimentos do conjunto de entrevistados. Tendo como referência a literatura que descreve os jovens contemporâneos observou-se que parte expressiva dos relatos foi ao encontro de aspectos apontados na referida literatura, ao mesmo tempo em que se identificaram expectativas e anseios desses jovens bastante semelhantes aos das gerações anteriores. A constatação de novidades e permanências no que tange as expectativas dos entrevistados motivou a organização do presente item em dois tópicos: o primeiro destacando os anseios por recompensas que pouco diferem daquelas das gerações anteriores, e o segundo apontando as expectativas dos jovens contemporâneos que seriam típicas dessa geração. Cada um dos tópicos foi subdividido em função 
dos temas que emergiram dos relatos e, para enunciar cada um, foram escolhidos fragmentos das falas dos entrevistados consideradas representativas dos temas identificados.

\section{Expectativas dos jovens profissionais: "como os nossos pais"}

\section{“Isso é que eu espero: crescimento." (E5)}

Apesar de estarem ingressando em um mundo do trabalho significativamente diferente do de seus pais e avós, caracterizado por relações de curto prazo, carreiras construídas em diagonal, sem fronteiras ou proteanas (DUTRA, 2010), estando a ascensão profissional muitas vezes condicionada à mudança de organização e não à promoção, foi recorrente nos relatos dos entrevistados o desejo de fazer carreira na empresa, como se nota nas seguintes observações:

Acho que o primeiro ponto seria a valorização do trabalho por meio de oportunidades de crescimento (E19).

Eu penso em trabalhar em uma empresa que eu pudesse chegar a um cargo alto. $\mathrm{O}$ ideal pra mim é trabalhar em uma empresa grande, porque na empresa pequena você fica meio restrito [...] que tenha espaço para eu crescer profissionalmente (E14).

Ter um plano de carreira mesmo, saber o que você vai poder fazer, que posição pode ocupar (E15).

Eu acho que todos pensam em crescer dentro de uma empresa, virar gerente de uma área, um diretor (E5).

Como profissional, espero ter oportunidade na empresa, que ela invista em mim, para crescer profissionalmente (E1).

Essa expectativa de crescimento profissional aproxima os jovens profissionais de seus antecessores, principalmente dos Boomers, caracterizados pela literatura como mais leais às organizações (SMOLA e SUTTON, 2002; CENNAMO e GARDNER, 2008; WONG et al., 2008). Esses jovens podem se frustrar com a dificuldade concreta de fazer carreira numa mesma organização, posto que a literatura que aborda as mudanças recentes das relações de trabalho é enfática ao afirmar que as carreiras organizacionais, típicas dos Boomers, estão em extinção e que, cada vez mais, caberá ao indivíduo gerenciar a própria carreira. Autores como Arthur e Rousseau (1996); Hall e Moss (1998) apontam para o declínio das carreiras organizacionais, que possibilitavam a ascensão periódica em uma mesma empresa e propiciavam a construção de vínculos de longo prazo entre trabalhador e organização. Além desse aspecto, cabe ressaltar que os jovens ainda poderão se frustrar com o tempo demandado para a ascensão profissional, pois, em seu imaginário, a expectativa é não só de fazer carreira nas organizações, mas também de progressão ágil, como exemplifica a fala de um participante: "espero ter oportunidade de ganhar dinheiro, de subir rápido na carreira, até porque no mercado financeiro a tendência é essa" (E6). Essa expectativa é ressaltada pela literatura que descreve os Yrs como demandantes de rápido crescimento dentro das organizações, (ALSOP, 2008; HUNTLEY, 2006; LOUGHLIN e BARLING, 2001; MUNRO, 2009). Pode-se dizer que, ao mesmo tempo em os jovens reproduzem o desejo de seus pais de fazer carreira nas organizações, afastam-se deles em sua noção de maturação profissional.

O desejo de fazer carreira aparece, em alguns casos, associado ao anseio de fazer parte de uma empresa de prestígio, que inspire admiração e orgulho de pertencer à mesma. Essa expectativa, que povoa o imaginário 
de certos jovens, da mesma forma em que esse senso de pertencimento foi importante para as gerações anteriores, revela que o trabalho ainda ocupa papel central na construção das identidades e que a importância da empresa reforça a valorização de seus integrantes (MOW, 1987). Um dos entrevistados sintetiza bem esse sentimento ao afirmar: "[...] também o fato de fazer parte realmente da empresa, que é uma sensação muito boa, que hoje em dia eu tenho" (E8).

Nos depoimentos, empresas tradicionais são mencionadas como referências, como lugares em que o entrevistado teria orgulho em trabalhar:

A Ford e a GM. Por serem empresas referência no mesmo mercado. Mas eu também adoro trabalhar na Nestlé, tenho uma admiração imensa pela empresa, além de ser também referência no mercado dela (E9).

\section{"Eu também quero estabilidade." (E21)}

Embora a literatura não acadêmica descreva a geração $\mathrm{Y}$ como menos inclinada a priorizar a estabilidade (ALSOP, 2008; ERICKSON, 2008; MUNRO, 2009), o desejo de fazer carreira, anteriormente abordado, aparece no relato de alguns entrevistados associado à intenção de fazê-lo em uma mesma organização e não em diversas empresas, como caracterizado na literatura que descreve a carreira sem fronteiras. $\mathrm{O}$ depoimento seguinte expressa essa junção de expectativas: "Que eu possa construir um plano de carreira nessa organização, pois eu não penso em trabalhar em uma empresa e trocar de empresa com frequência (E12).

A expectativa por segurança no trabalho aparece com frequência no discurso dos participantes, apesar de sua condição de profissional ainda em formação, contrariando, portanto, a forma como a literatura tende a caracterizá-los:

Acho que um fator de estabilidade. Aqui no Brasil isso é um pouco mais difícil comparativamente a outros países, até parece um sonho, né? Existem fatores externos que desestabilizam muito as empresas do Brasil e que poderiam ser contornados (E17).

Não sei, talvez porque eu veja muitas pessoas reclamando dos salários, das condições de trabalho e já nas empresas privadas no mesmo cargo você ganha mais, mas eu também quero estabilidade (E20).

Também é importante ter certa estabilidade, pois isto afeta o ambiente de trabalho (E20).

A valorização da estabilidade é uma dimensão que também aproxima os futuros profissionais de seus antecessores, em especial dos Baby Boomers (SMOLA e SUTTON, 2002; CENNAMO e GARDNER, 2008; WONG et al., 2008) sugerindo uma capacidade menor de lidar com risco do que aquela associada comumente a essa geração, tida como inquieta. A sua preocupação com o futuro e com a estabilidade no emprego pode estar ligada às experiências vivenciadas pelos pais, como sugere uma participante: "eu também acho importante a estabilidade do emprego. Eu não fiz economia, porque o meu pai trabalhava no mercado financeiro e era muito instável. Ele não tinha uma renda fixa e eu quero ter uma renda fixa, pode até ter comissão para me motivar, mas tem que ter um salário fixo" (E14).

O desejo por perenidade na relação de trabalho pode ser, também, um traço que ao aproximar as novas gerações das anteriores, revele que a segurança no emprego seja um valor atemporal, um anseio comum aos indivíduos, independente do momento em que vivam. 


\section{"Eu espero ter um salário bom." (E13)}

Receber bons salários e benefícios também é uma importante expectativa dos entrevistados, o que se alinha parcialmente com as descrições populares dessa geração, caracterizada como ambiciosa, ao mesmo tempo em que a aproxima das gerações anteriores:

Eu espero ter um salário bom, ter vários benefícios. Como no evento que teve das 25 melhores empresas pra se trabalhar: elas têm benefícios - transporte, alimentação, seguro social (E13).

Remuneração eu acho que é o mais importante (E14).

Acredito que [o salário] tem que estar adequado ao mercado, compatível com o que eu faço e ajustado ao que as outras empresas oferecem para a mesma função. Isso é importante até para eu me sentir motivada dentro da empresa (E12).

A expectativa por um bom salário aparece também como um elemento motivador de busca por melhores oportunidades: "a partir do momento que eu receba uma oferta melhor e essa diferença pague um curso como esses [pós-graduação] eu com certeza trocaria de empresa” (E21).

A valorização da remuneração revela que essa forma de recompensa tem impacto na motivação dos novos entrantes, sendo esse um aspecto que não deve ser negligenciado pelas organizações que desejam atrair e reter esses indivíduos.

\section{"Você sempre espera crescer em uma empresa e ser reconhecido." (E4)}

Conforme ressaltado na literatura (ALSOP, 2008; HUNTLEY, 2006; LOUGHLIN e BARLING, 2001; MUNRO, 2009), um traço marcante nesses indivíduos é a necessidade de crescimento e reconhecimento, o que não chega a ser uma novidade, pois desde os clássicos estudos sobre motivação de Maslow, Herzberg e McClelland que essas necessidades são identificadas como motivadoras do desempenho individual. Essas expectativas apareceram com frequência nos relatos dos entrevistados, que esperam valorização, oportunidades de desenvolvimento profissional e investimento das organizações as quais venham a se ligar. As falas seguintes exemplificam essas expectativas:

Espero fazer o trabalho e ser recompensado por isso, ter um reconhecimento financeiro e moral, tipo elogios (E3).

[...] que veja em mim capacidade e que haja um investimento em mim (...) (E12).

Eu gostaria de ter a possibilidade de mostrar o meu trabalho, de seu trabalho poder aparecer, que seja uma coisa valorizada [...] também acho que deve dar ênfase na política de premiação e reconhecimento (E10).

Outra coisa que eu espero, é que a empresa não me veja somente como uma profissional do presente, que a empresa me aproveite, que veja em mim capacidade e que haja um investimento em mim para que eu possa dar o retorno (E12).

Todavia, cabe ressaltar que a questão do reconhecimento parece se colocar de forma peculiar para a nova geração: recompensas tangíveis, como aumento salariais, ou simbólicas, como destaque ao funcionário do 
mês, não parecem ser suficientes para esses jovens, que por vezes parecem ansiar por gratificações ainda mais amplas no trabalho. Quiçá em função das dinâmicas vivenciadas nas relações parentais, os Yrs esperam recompensas por suas realizações também sob a forma de atenção e feedback constantes, como sugerem os relatos, a seguir:

Eu gostaria muito de chegar a uma empresa que tivesse um gestor que pudesse me ajudar como profissional. Que ele tivesse um papel de, não só como avaliador, que ele pudesse me direcionar dentro da empresa a ter um bom aproveitamento. Seja me dando um feedback positivo ou negativo para que eu melhore a minha atuação (E12).

Ou seja, gostaria de trabalhar numa empresa que tenha como objetivo principal desenvolver o funcionário e o bem-estar do funcionário (E3).

Gostaria de uma empresa que me dê à sensação de que sou valorizado (E15).

[...] que você possa ter qualidade de vida (E22).

O equilíbrio entre vida profissional e pessoal, destacado na literatura como uma preocupação dos mais jovens, aparece nos depoimentos de vários entrevistados, reforçando a importância que a noção de qualidade de vida tem para esses profissionais em formação. Esse desejo, ao mesmo tempo em que os distingue dos Boomers, que pareciam ter mais dificuldades em conciliar a vida profissional com a pessoal, aproxima-os dos Xrs, aparentemente mais preocupados com esse o equilíbrio (SMOLA e SUTTON, 2002; CENNAMO e GARDNER, 2008; WONG et al., 2008):

A empresa deve perceber que nós não devemos dar a vida toda para a empresa (E13).

Ter tempo com minha família, ter respeito aos horários, justamente por isso. Poder ter a oportunidade de fazer uma atividade física. Ter uma interação entre os funcionários e as famílias também, de forma que a empresa tentasse integrar essas duas variáveis. Também o fato de trabalhar perto de casa porque você perde muito tempo no trânsito mesmo. Você muitas vezes acaba perdendo três, quatro horas só pra se locomover até o trabalho (E15).

É você ter o seu tempo pra fazer as suas coisas, aquilo que você gosta. Pela competitividade você acaba se dedicando demais e perdendo isso, que é uma coisa do sistema capitalista mesmo, essa competição e tal, nós acabamos nos submetendo mesmo. Acho que nós deveríamos rever isso (E17).

\section{Expectativas dos jovens profissionais: "amanhã será um lindo dia..."}

Ao mesmo tempo em que apontam expectativas que não os distinguem das gerações anteriores, os entrevistados revelam anseios que podem ser vistos como típicos de sua geração. Esperançosos quanto ao seu futuro profissional, esses jovens vislumbram desafios, prazer, equilíbrio entre vida profissional e pessoal, reconhecimento, além de relações amistosas e éticas no ambiente de trabalho. Os relatos a seguir destacam observações dos participantes que seriam peculiares ao grupo, encontrando ressonância na literatura que os descreve em sua peculiaridade. 


\section{"Que você sinta prazer mesmo." (E8)}

Considerados hedonistas, com elevada necessidade de satisfação pessoal (TWENGE e CAMPBELL, 2008), os jovens entrevistados parecem realmente associar prazer e realização ao trabalho, talvez por isso, tendam a idealizar as características, as condições e as relações de trabalho futuras. Anseiam não só por satisfação, mas também por estímulos frequentes das empresas, rejeitando tarefas rotineiras e ansiando por novos desafios, como os depoimentos seguintes indicam:

O trabalho dos meus sonhos é fazer algo que eu goste em uma empresa que incentive que eu cresça na função que eu desempenho (E11).

Que a empresa, além de investir em mim, me faça ter vontade de continuar trabalhando lá [...] Não precisa de ninguém te puxando, não é uma obrigação, é uma coisa que você faz por prazer (E1).

Bom, eu acho que todo mundo busca desempenhar uma atividade que goste, que você sinta prazer mesmo, se sinta confortável [...] eu saí de uma função super-rotineira que eu desempenhava e fui para uma área completamente diferente que é gerenciamento de projetos (E8).

Eu não quero nada monótono e nem com muita pressão (E14).

É uma coisa que você faz por prazer e ainda recebe dinheiro por fazer de forma bem feita (E1).

Esse hedonismo também aparece no desejo por um ambiente de trabalho bonito e fisicamente agradável: "ou seja, fornecerem aos funcionários todos os insumos materiais que os funcionários possam precisar computadores modernos, um ambiente bonito, iluminado, espaço físico legal, porque isso motiva os funcionários" (E3).

\section{"[...] flexibilidade em tudo." (E13)}

Além do prazer, a flexibilidade nas condições e nas relações de trabalho, apontada na literatura como expectativa comum aos jovens (ALSOP, 2008; HUNTLEY, 2006; LOUGHLIN e BARLING, 2001; MUNRO, 2009), aparece com bastante intensidade nas entrevistas, endossando essa premissa. Os trechos seguintes reforçam a demanda dessa geração por flexibilidade e liberdade no trabalho.

Eu gostaria de encontrar flexibilidade. Eu trabalho numa empresa muito burocratizada, que é a H.Stern, você acaba trabalhando muito e quando você precisa sair mais cedo é mais difícil (E21).

Em relação ao ambiente de trabalho, de eles trabalharem de forma mais informal, cultura informal, você trabalhar, ir para empresa quando tem vontade de ir, desde que sejam cumpridos os prazos, acho que isso também é importante, ter essa flexibilidade de trabalhar do jeito que você quiser (E1).

Eu espero que o trabalho seja do jeito que eu desempenho hoje lá na IBM, porque eu tenho uma liberdade muito grande no trabalho, eu tenho um horário muito grande de dez da manhã às cinco da tarde pra trabalhar, mas eu não tenho que cumprir esse horário 
necessariamente porque eu trabalho por banco de horas eu acho que quanto maior a liberdade mais respeito você tem pela empresa e consequentemente rende melhor (E7).

Acho que uma empresa com práticas modernas de administração, como por exemplo, ter uma comunicação horizontal com os funcionários, que dê uma maior flexibilidade de horário, que leve mais em conta aspectos pessoais do funcionário (E8).

Em todas as experiências que eu tive os chefes ficam monitorando muito, isso não me atrai de forma alguma. Além disso, os horários não são flexíveis (E20).

A flexibilidade no trabalho pode ser considerada, portanto, como um anseio típico dos Yrs, pois a literatura que caracteriza as gerações antecessoras não identifica essa expectativa, entre Boomers e Geração X (SMOLA e SUTTON, 2002; CENNAMO e GARDNER, 2008; WONG et al., 2008).

\section{"Um bom ambiente, bom relacionamento com as pessoas." (E5)}

Um bom ambiente de trabalho, marcado por bons relacionamentos interpessoais, cooperação e respeito, é um anseio comum aos entrevistados. A menção ao bom ambiente, aos bons relacionamentos é frequente nos relatos, corroborando a ideia presente na literatura que os caracteriza (MACHY, GARDNER e FORSYTH, 2008), de que estes jovens teriam níveis talvez ainda mais altos de motivação por oportunidades de interação com outras pessoas no trabalho do que seus antecessores:

Você se sentir num ambiente acolhedor, que você saiba que as pessoas a sua volta estão ali pra se ajudar, e não pra competir, em princípio (E4).

Um ambiente bom para trabalhar. Espero trabalhar com pessoas que saibam se relacionar com personalidades diferentes (E16).

O ambiente de trabalho ser bem favorável, ser bem harmônico (E2).

Eu gostaria de trabalhar em uma empresa em que eu pudesse ter amigos e companheiros de trabalho (E10).

Muito embora gerações anteriores dessem importância às relações interpessoais no trabalho (SMOLA e SUTTON, 2002; CENNAMO e GARDNER, 2008; WONG et al., 2008), o destaque dado a esse aspecto, como representativo dos anseios dos Yrs, está baseado nos relatos sugestivos de que a interação de qualidade no ambiente profissional parece ser particularmente valorizada. Os entrevistados mencionam, com alguma frequência, a expectativa por encontrar ambientes cooperativos, fazendo inclusive algumas críticas à competitividade nas organizações:

Pessoas que cooperem com as outras, pessoas que se preocupem com o desenvolvimento das outras. Com certeza deve haver concorrência entre os funcionários, mas eu espero que a empresa trabalhe no sentido de minimizar ações desleais devido à competição (E11).

Existe um problema muito grande atualmente que é a competição até dentro da própria empresa mesmo, de certa forma isso atrapalha a organização. É mais prejudicial que positiva. Eu gosto de competição, mas a competição não é boa quando não é uma situação "win-win", ou seja, depende das regras do jogo mesmo (E17). 
A valorização da cooperação e do trabalho em equipe vai de encontro a uma característica que costuma ser associada a esses indivíduos: o individualismo. Apesar de retratada como mais individualistas do que seus pais e avós, o discurso dos entrevistados revela, em vários casos, um comportamento gregário e um repúdio à competição exacerbada.

\title{
“E a tal da responsabilidade social não deve ficar só no discurso." (E13)
}

A preocupação com questões sociais e ambientais faz parte do universo desses jovens, endossando considerações da literatura recente sobre os Y, que os retrata como mais sensíveis a essas causas (ALSOP, 2008; HUNTLEY, 2006). Os entrevistados mencionaram, com relativa frequência, essa preocupação:

É uma coisa que eu acho muito importante numa empresa, até gostaria de trabalhar com isso, para mim as empresas não têm que visar só o lucro e trabalhar também a melhora do capital social e do meio ambiente (E4).

A empresa deve ter também uma preocupação com o impacto que causa no meio ambiente, como a Shell que trabalha com combustíveis e outros materiais que podem representar um risco, ela deve ter ações para minimizar os impactos que ela causa à natureza (E11).

De acordo com a literatura citada, a reputação das empresas influencia consideravelmente os jovens profissionais no momento de escolher uma determinada organização para trabalhar. Tais ideias aparecem no discurso dos participantes - empresas consideradas éticas teriam a sua preferência na escolha por emprego:

\begin{abstract}
Você saber que você trabalha numa empresa que cumpra o seu papel na sociedade também te dá esse orgulho. E ao falar sobre o papel na sociedade das empresas me veio à cabeça o fator ambiental também, o momento ambiental que nós estamos vivendo [...] Outra coisa também, eu não trabalharia na Souza Cruz, por exemplo [...] Ela vende um produto que faz mal às pessoas (E16).
\end{abstract}

Valores como "Honestidade, clareza nas ações, transparência" (E11), também aparecem nos relatos dos entrevistados, reforçando a relevância de condutas éticas, pelo menos para parte dos integrantes da nova geração de profissionais.

\section{Discussão dos Resultados e Conclusões}

Em função de mudanças observadas na sociedade, sobretudo culturais e tecnológicas, muitos autores vêm afirmando que os jovens da geração Y teriam atitudes e comportamentos no trabalho bastante distintos de seus antecessores. As diferentes expectativas desses jovens estariam associadas aos seus valores sobre o trabalho, desenvolvidos em função de mudanças no próprio sentido do trabalho, do aumento no número de casais com dupla carreira profissional e de famílias formadas por único cônjuge e suas expectativas por maior equilíbrio entre vida pessoal e vida no trabalho, da intensificação no uso de mídias eletrônicas, entre outros fatores (CENNAMO e GARDNER, 2008; TWENGE e CAMPBELL, 2008).

No entanto, apesar das diferenças entre as gerações apontadas em trabalhos jornalísticos, a análise das entrevistas sugere que há mais em comum entre os nossos $\operatorname{Yrs}$ e seus antecessores do que essa literatura nos faria crer (ALSOP, 2008; MUNRO, 2009, TWENGE e CAMPBELL, 2008). Contrariando as observações de alguns desses autores, a segurança no trabalho aparece como um elemento ainda importante e valorizado 
pelos jovens. As recompensas tangíveis, como salários e benefícios se apresentam nos discursos dos jovens como elementos motivacionais, aproximando-os das gerações passadas. Até o seu notável desejo por progressão na carreira, muito embora alinhado com as observações de outros estudos sobre a geração Y (WONG et al., 2008), se dá numa carreira idealizada em termos de vínculos de longa duração. Tal carreira se parece muito mais com a progressão vertical experimentada pelas gerações anteriores nas grandes corporações do que com as carreiras sem fronteiras, construídas em diagonal, com base em relações de curto prazo, observadas na atualidade (DUTRA, 2010). A despeito dessa expectativa de crescimento ser ou não típica da fase no ciclo de vida em que se encontram, é interessante observar que o desejo construído por estes jovens se ancora em um ideal que estaria em declínio nas relações de trabalho de hoje, dado que a ascensão muitas vezes está condicionada à mudança de organização e não à promoção (DUTRA, 2010; BALASSIANO e COSTA, 2006). A distância entre as expectativas dos jovens e as oportunidades típicas que a eles se apresentarão constitui uma barreira em potencial para o alinhamento pessoa-trabalho, com desdobramentos particularmente críticos para o comprometimento de uma geração que parece reagir mais às incongruências entre expectativas e experiências do que os seus antecessores (CENNAMO e GARDNER, 2008).

Estes jovens também esperam realizar tarefas variadas e estimulantes, ratificando algumas das observações de ensaios jornalísticos a respeito dessa geração, tida como mais inclinada a apreciar papéis e metas de trabalho desafiadoras (ALSOP, 2008; MUNRO, 2009). Nota-se nos discursos, de forma bastante acentuada, o desejo de que tais experiências no universo do trabalho sejam principalmente gratificantes em diversos aspectos, desde a experiência do prazer na realização de tarefas, da liberdade para decidir quando e como realizá-las e de equilíbrio entre a vida profissional e pessoal, até a satisfação através do reconhecimento de suas realizações e da construção de relações de trabalho cooperativas em organizações genuinamente preocupadas com a sociedade. Nesse sentido, os discursos dos entrevistados reforçam as descrições da literatura sugestivas de que esta seria uma geração de indivíduos com elevada necessidade de satisfação, ambiciosos, desejosos de novidades, gregários e preocupados com a cidadania corporativa (ALSOP, 2008; WONG et al., 2008). Porém, estes jovens esperam encontrar um ambiente de trabalho altamente idealizado, bastante diferente do emprego médio usualmente vivenciado em grande parte das organizações até mesmo por profissionais mais experientes e capacitados. Expectativas tão elevadas implicam riscos maiores de frustração e desapontamento, bem como do senso de quebra no contrato psicológico de trabalho, fatores estes que, se não forem administrados, podem também constituir ameaças ao comprometimento desses jovens (MEYER, 2009).

Do ponto de vista teórico, as observações desta pesquisa oferecem algum suporte à noção de que jovens funcionários talvez estabeleçam contratos psicológicos com a organização que favorecem a liberdade, o status e o envolvimento social. Ao mesmo tempo, no entanto, indicam que o novo parece coexistir com o tradicional, pois anseios contemporâneos combinam-se a desejos comuns às gerações anteriores, reforçando a percepção de que existem expectativas relacionadas ao trabalho que subsistem, a despeito de mudanças objetivas na esfera produtiva. Essa observação ajudaria a explicar a relativa ausência de diferenças tão marcantes entre as gerações nos estudos acadêmicos que investigam valores sobre o trabalho (MACHY, GARDNER e FORSYTH, 2008). Porém, é interessante observar que as expectativas desses jovens, tidas como típicas de sua geração, parecem estar em grande parte centradas na satisfação das próprias necessidades e no desejo de gratificação. Esta tendência parece alinhada com os resultados de Twenge e Campbell (2008) que apontam para um aumento lento, porém sistemático de traços psicológicos como a autoestima e o narcisismo, e, por conseguinte, do individualismo nos jovens das novas gerações. Observa-se assim que há uma lacuna a ser preenchida por perspectivas teóricas que melhor expliquem em que dimensões os novos profissionais são de fato distintos dos demais e por quê.

É interessante observar também que ao longo do tempo e de uma geração para a outra, parece que o peso relativo entre deveres e direitos vai trocando de posição na balança das relações de trabalho. Entre os Boomers aparentemente havia muito mais peso no prato dos deveres, sobretudo a disposição para se sacrificar pelo emprego e pela carreira vertical. O principal direito almejado era exatamente permanecer e 
crescer verticalmente em um sistema. Na geração seguinte, os Xrs, o prato dos deveres parece ter ficado um pouco mais leve, pois que condicionados à vigência de interesses e vantagens transacionadas pelo indivíduo com a organização. $\mathrm{O}$ prato dos direitos parece ganhar mais peso também, com expectativas de maior participação, de desenvolvimento de competências e de qualidade de vida. No entanto, talvez seja entre os Yrs que o prato dos direitos tenha ganhado mais reforços, dado que aparentemente os contratos psicológicos dessa geração incluem um repertório ampliado de expectativas (prazer, gratificação, liberdade, respeito aos seus limites, relações de qualidade etc). Nesse sentido, embora antigos ideais das gerações passadas sejam compartilhados pela geração Y, o seu perfil psicológico parece envolver algumas características particulares que podem representar um desafio para os gestores no contexto corporativo. Chefes de gerações passadas talvez encontrem dificuldades para lidar com os níveis elevados de hedonismo e as altas expectativas desses jovens, sejam eles Boomers acostumados com o sacrifício pelo cumprimento de obrigações e garantias de segurança, sejam Xrs com seu pragmatismo e cinismo, mas talvez menos preparados para corresponder aos mentores prototípicos, participativos e benevolentes, que os Yrs desejariam ter.

Do ponto de vista prático, o gerenciamento dos contratos psicológicos e esforços no sentido de minimizar a falta de alinhamento para novos profissionais parece ser uma tarefa essencial nas organizações que pretendam fomentar o comprometimento desse grupo. As expectativas pouco realistas que os jovens profissionais levam para o trabalho podem exigir das empresas respostas que acomodem ou redimensionem seus anseios. No entanto, é possível que a importância relativa das recompensas tangíveis e intangíveis obtidas no trabalho varie ainda mais entre indivíduos do que entre gerações. Portanto, parece recomendável que os programas e políticas de gestão de pessoas não desprezem as necessidades de cada um em favor de uma visão estereotipada, pois generalista, dos Yrs, alimentada principalmente pela popularidade do assunto na mídia. Além disso, seria recomendável que as empresas procurassem compreender e administrar as expectativas de seus jovens funcionários ainda na fase inicial na construção do contrato psicológico, para evitar conflitos e frustrações. A divulgação ineficiente e por vezes ambígua de valores e políticas institucionais pode reforçar nos jovens expectativas pouco realistas. A boa comunicação combinada com o uso de técnicas robustas de recrutamento e seleção podem ser úteis para evitar a rotatividade.

De forma conclusiva, cabe ressaltar que este trabalho buscou especificamente investigar as expectativas dos jovens no tocante a recompensas tangíveis e intangíveis obtidas no trabalho. Embora a identificação dos fatores que influenciam as atitudes das novas gerações seja uma iniciativa relevante, ela está além do escopo desse estudo. Trabalhos futuros devem aprofundar a questão, procurando compreender, por exemplo, que valores sobre a vida e o trabalho estariam sendo priorizados pelas novas gerações. Apesar de reveladores, os resultados deste estudo são também limitados, em face da natureza qualitativa da pesquisa, mais afeita à observação de aspectos subjetivos relativos ao trabalho do que à comparação sistemática de grupos sociais. Estudos futuros podem aprofundar a análise desta questão através de desenhos quantitativos que visem verificar a importância relativa de recompensas específicas para indivíduos de diferentes gerações, bem como diferenças sistemáticas em seus valores e atitudes. Além disso, parece também relevante a busca, através de pesquisas qualitativas, de uma melhor compreensão do significado atribuído pelos jovens a um trabalho "com mais desafios", e do que significa para eles "crescer profissionalmente" numa empresa. A exploração mais aprofundada daquilo que é percebido pelos jovens como sendo suas obrigações para com seus empregadores seria também uma interessante vertente de pesquisa. 


\section{Referências Bibliográficas}

ALLEN, N. J.; MEYER, J. P. The measurement and antecedents of affective, continuance, and normative commitment to the organization. Journal of Occupational Psychology, v.63, p. 1-18, 1990.

ALSOP, R. The Trophy Kids Grow Up: How the millennial generation is shaking up the workplace. EUA: JosseyBass, 2008.

ARTHUR, M.; ROUSSEAU, D. The Boundaryless Career: A New Employment Principle for a New Organizational Era. New York: Oxford University Press, 1996.

BALASSIANO, M.; COSTA, I.S.A. (Org.). Gestão de Carreiras: dilemas e perspectivas. São Paulo: Atlas, 2006.

BERMAN, M. Tudo o que é sólido desmancha no ar. São Paulo: Companhia das Letras, 1988.

BLAU, G. Testing for a four-dimensional structure of occupational commitment. Journal of Occupational and Organizational Psychology, v.76, p. 469-488, 2003.

CASTEL, R. As metamorfoses da questão social: uma crônica do salariado. Petrópolis: Vozes, 1998.

CENNAMO, L.; GARDNER, D. Generational differences in work values, outcomes and person-organization values fit. Journal of Managerial Psychology, v. 23, n.8, p.891-906, 2008.

COOPER-HAMIK, A.; VISWESVARAN, C. The construct of work commitment: Testing an integrative framework. Psychological Bulletin, v.131, p.241-259, 2005.

CRESWELL, J. Qualitative Inquiry and Research Design. Thousand Oaks, CA: Sage, 2007.

DEFILLIPI, R.J.; ARTHUR, M.B. The boudaryless career: a competency-based perspective. Journal of Organizational Behavior, v.15, p.307-324, 1994.

DUTRA, J. S. Gestão de Carreiras na empresa contemporânea. São Paulo: Atlas, 2010.

EDWARDS, J. Person-Job Fit: A Conceptual Integration, Literature Review and Methodological Critique. In: COOPER, C.L.; ROBERTSON, I.T. International Review of Industrial and Organizational Psychology. Chicherter, UK: Wiley, 1991.

ERICKSON, T. Plugged in: the generation Y guide to thriving at work. Boston. Harvard Business Press, 2008.

HALL, D.T.; MOSS, J.E. The new protean career contract: helping organizations and employees adapt. Organizational dynamics, v.26, n.3, p.22-36, 1998.

HOWARD, A. A Framework for Work Change. In: HOWARD, A. The Changing Nature of Work. San Francisco: Jossey-Bass Publishers, 1995.

HUNTLEY, R. The World according to Y: Inside the New Adult Generation. Sydney: Allen \& Unwin, 2006.

KALLABERG, A.; LOSCOCCO, K. Aging Values and rewards: Explaining Age Differences in Job Satisfaction. American Sociological Review, v.48, p.78-90, 1983.

KLEIN, H. J.; MOLlOY, J. C.; COOPER, J. T. Conceptual foundations: Construct definitions and theoretical representations of workplace commitment. In: KLEIN, H.J.; BECKER, T.; MEYER, J.P. (Eds.), Commitment in organizations: Accumulated wisdom and new directions. London: Routledge/Taylor \& Francis, 2009.

LOUGHLIN, C.; BARLING, J. Young workers' values, attitudes, and behaviours. Journal of Occupational and Organizational Psychology, v.74, n.4, p. 543-558, 2001. 
MACHY, K., GARDNER, D., FORSYTH, S. Generational differences at work: introduction and overview. Journal of Managerial Psychology, v.23, n.8, p.857-861, 2008.

MATHIEU, J. E.; ZAJAC, D. M. A review and meta-analysis of the antecedents, correlates, and consequences of organizational commitment. Psychological Bulletin, v.108, p.171-194, 1990.

MEYER, J. P. Commitment in a Changing World of Work. In: KLEIN, H.J.; BECKER, T.; MEYER, J.P. (Eds.). Commitment in organizations: Accumulated wisdom and new directions. London: Routledge/Taylor \& Francis, 2009.

; et al. Affective, continuance, and normative commitment to the organization: A meta-analysis of antecedents, correlates, and consequences. Journal of Vocational Behavior, v.61, p.20-52, 2002.

1997.

; ALLEN, N. Commitment in the workplace: Theory, research, and application. Thousand Oaks, CA: Sage,

MOW International Research Team. The Meaning of Work. London: Academic Press, 1987.

MOWDAY, R. T., STEERS, R. M., PORTER, L. W. The measurement of organizational commitment. Journal of Vocational Behavior, v.14, p.224-227, 1979.

MUNRO, R. C. Mentoring Needs and Expectations of Genaration-Y. Human Resources Practitioners: Preparing the Next Wave of Strategic Business Partners. Journal of Management Research, v.1, n.2, 2009.

NORD, W.; BRIEF, A. On the Reciprocal Relationship between the Meaning of Work and Political Economy. In: BRIEF, A.; NORD, W. Meanings of Occupational Work. Massachusetts: Lexington Books, 1990.

Books, 1990.

et al. Work Values. In: BRIEF, A.; NORD, W. Meanings of Occupational Work. Massachusetts: Lexington

PROSERPIO, L.; GIOIA, D. Teaching the Virtual Generation. Academy of Management Learning \& Education, v.6, n. 1, p.69-80, 2007.

ROKEACH. The Nature of Human Values. New York: Free Press, 1973.

SAKS, A.; ASHFORTH, B. A Longitudinal Investigation of the Relationship Between Job Information Sources, Applicant Perceptions of Fit and Work Outcomes. Personnel Psychology, v. 50, p.395-426, 1997.

SMITH, D.; TZINER, A. Moderating Effects of Affective Disposition and Social Support on the Relationship Between Person-Environment Fit and Strain. Psychological Reports, v.82, p. 963-983, 1998.

SMOLA, K.W.; SUTTON, C.D. Generational Differences: revisiting generational work values for the new millenium. Journal of Organizational Behavior, v.23, p.363-382, 2002.

TWENGE, J. M.; CAMPBELL, S. M. Generational differences in psychological traits and their impact on the workplace. Journal of Managerial Psychology, v.23, n.8, p.862-877, 2008.

VAN DER VELDE, M.; FEIJ, J.; VAN EMMERIK, H. Change in work values and norms among Dutch young adults: aging or societal trends. International Journal of Behavioral Development, v.22, n.1, p.55-76, 1998.

WONG, M. et al. Generational differences in personality and motivation: do they exist and what are the implications for the workplace? Journal of Managerial Psychology, v.23, n.8, p.878-890, 2008. 